\title{
REACTION OF CHALCONES WITH BASIC HYDROGEN PEROXIDE: A STRUCTURE AND REACTIVITY STUDY
}

\author{
Herman Holt, Jr.', Regan LeBlanc ${ }^{2}$, John Dickson ${ }^{2}$, Toni Brown ${ }^{2}$, Jessica R. Maddox ${ }^{1}$, Moses Lee ${ }^{2}$ \\ Moses.Lee@furman.edu

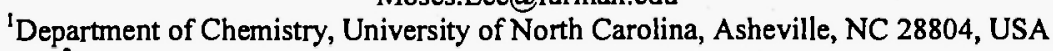 \\ ${ }^{2}$ Department of Chemistry, Furman University, Greenville, SC 29613, USA
}

\begin{abstract}
Chalcone epoxides are important intermediates for the synthesis of 3,5-diarylpyrazoles. Twenty different chalcones were oxidized with hydrogen peroxide and potassium carbonate in order to produce the corresponding epoxides. The electronic nature of the substituents on the A- and B-ring of the chalcones significantly affected the reaction outcome: (i) electron donating groups on the Aand B-ring aided the reversion of the chalcones to the corresponding benzaldehydes, (ii) electron withdrawing groups on the B-ring promoted formation of the desired chalcone-epoxides in high chemical yields, and (iii) the presence of electron withdrawing groups (A-ring of the chalcones), regardless of the substituents on the B-ring, produced a mixture of epoxide, unreacted chalcone, benzaldehyde and acetophenone.
\end{abstract}

\section{Introduction}

Chalcones (1,3-diaryl-2-propen-1-ones) are readily prepared from the Claisen-Schmidt condensation of benzaldehydes and acetophenones, ${ }^{\prime}$ and they are being investigated as analogs of the potent anticancer agent, combretastatin A4 (CA-4, Fig. 1). ${ }^{2,3}$ In accordance with CA-4, chalcones bind to the colchicine site of tubulin and inhibit the formation of the mitotic spindle in cancer cells. ${ }^{4}$ As a result, chalcones have significant cytotoxicity against tumor cells grown in culture, ${ }^{3,5}$ and structure-activity relationship studies have suggested that the 1,3-diphenyl substituted propenone backbone is crucial for activity. ${ }^{6}$ In order to develop novel chalcone derivatives with anti-cancer properties, one strategy is to convert the enone functionality into a heterocyclic unit, such as a pyrazole. Prior to our recent disclosure, the resulting 3,5-diarylpyrazole derivatives of chalcones have not been investigated as potential anti-cancer agents. ${ }^{7}$ This drug design strategy has been successfully applied to the combretastatins, from which a tetrazole analog of CA-4 was discovered to possess potent anticancer activity.

A convenient synthesis of 3,5-diarylpyrazoles involves the reaction of chalcone epoxides with hydrazine, ${ }^{9}$ thereby necessitating an efficient method for producing the starting epoxides from their respective chalcones (Fig-1). A number of methods for the preparation of chalcone epoxides have been developed and reviewed, ${ }^{10}$ including the synthesis of optically active epoxides. ${ }^{100}$ The WeitzScheffer basic hydrogen peroxide method, however, remains the most convenient. To our knowledge, there has not been a study conducted to investigate the effects of substituents on the epoxidation of chalcones and the possibility of different reaction outcomes. 


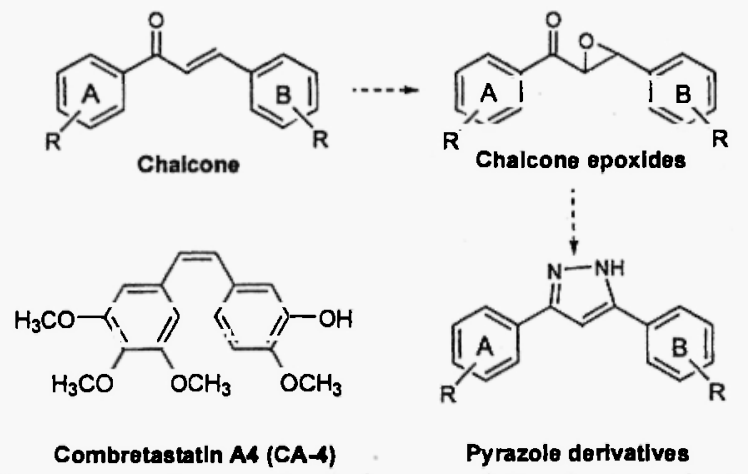

Figure-1: Structures of a generic chalcone and Combretastatin A4 (CA-4).

As part of a biological study of 3,5-diarylpyrazoles, twenty different chalcone epoxides derived from their respective chalcones (1 - 20) (Fig. 2) were required, which included electron donating and/or withdrawing groups on both the A- and B-rings. ${ }^{7}$ This diverse group of chalcones provided an opportunity for establishing a structure-reactivity relationship. Our interest in these studies was inspired by several initial unexpected discoveries. Reaction of chalcone 11 (300 mg scale) with hydrogen peroxide, potassium carbonate and methanol produced the corresponding epoxide exclusively (Fig. 3). ${ }^{11}$ However, in the case of chalcone 16, no epoxide was isolated and only 3,4dimethoxybenzaldehyde was formed. Furthermore, oxidation of chalcone 1 gave a mixture of epoxide and benzaldehyde. ${ }^{9}$
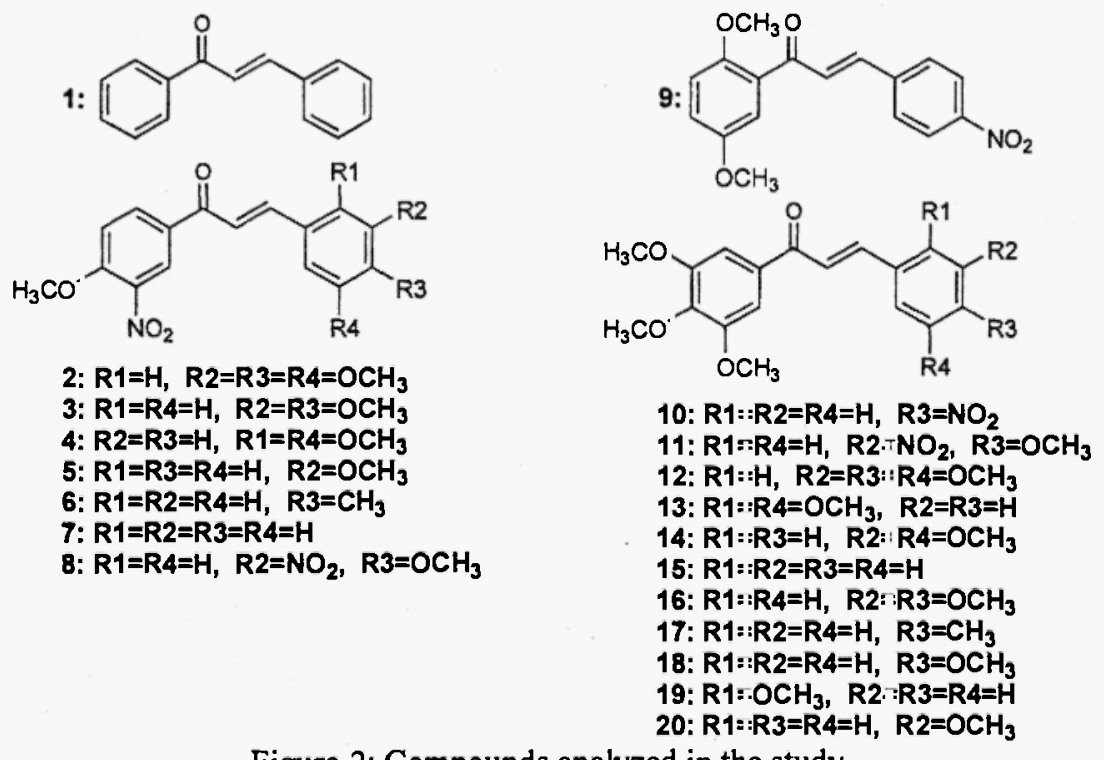

Figure-2: Compounds analyzed in the study.

\section{Results and Discussions}

A detailed study on the chemical reactivity of twenty different chalcones (1-20, Fig-2) with $\mathrm{H}_{2} \mathrm{O}_{2}$ and $\mathrm{K}_{2} \mathrm{CO}_{3}$ was conducted under identical reaction conditions: concentration, temperature, reaction time, and extraction procedure. ${ }^{12}$ Characteristic NMR signals for the trans-chalcone, $(\sim 7.4 \mathrm{ppm}, \mathrm{d}, J=\sim 16$ 
$\mathrm{Hz}$ ), epoxide ( $\sim 4.3 \mathrm{ppm}$, two doublets, $J-\sim 2 \mathrm{~Hz}$, that sometimes can overlap), benzaldehyde ( $\sim 9.8$ ppm, s) and acetophenone ( $2.6 \mathrm{ppm}, \mathrm{s})$ were readily discerned in the mixture by comparison to authentic samples. The relative percentages of each species were quantified, using the NMR spectra of the twenty different crude reaction mixtures. The results, given in Table 1, provided evidence that formation and isolation of the desired epoxide was dependent upon the nature of the substituents; three reactivity trends were observed. Structures of the epoxides were confirmed by NMR, IR and high resolution mass spectral analyses, as reported previously. ${ }^{7}$ The chalcones, benzaldehydes and acetophenones were identified by comparing the data to NMR spectra obtained from authentic samples.

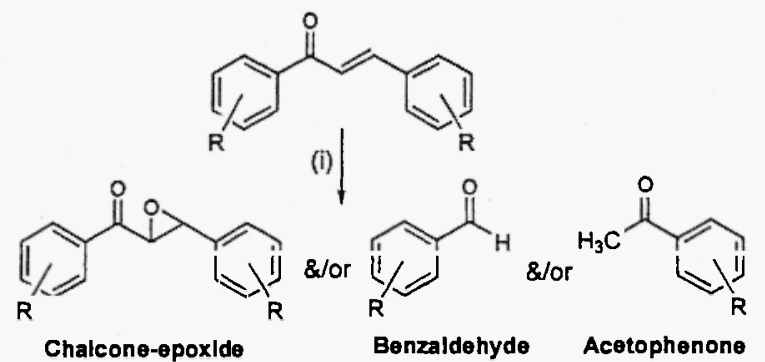

Figure-3. Reaction of a chalcone to produce: epoxide, benzaldehyde and acetophenone.

(i) $\mathrm{K}_{2} \mathrm{CO}_{3}, \mathrm{MeOH}, \mathrm{RT}, 35 \% \mathrm{H}_{2} \mathrm{O}_{2}, 15 \mathrm{~h}$.

\section{(i) Electron donating groups on the A- and B-ring}

Reactivity of the chalcone to form the epoxide was independent on the position of the A-ring substituents. If the chalcone contained a single- or multi-methoxy group(s) in the A-ring, epoxide formation was dependent upon the substituents on the B-ring. The isolated product was not only the epoxide, but the original benzaldehyde was also formed. In some cases, e.g. compounds 12 and $\mathbf{1 6}$, the corresponding benzaldehyde was the major product formed in the reaction. The ratio of benzaldehyde to epoxide was observed by NMR, and the results correlated with the substitution pattern of the B-ring. For example, in the reaction of a B-ring para-methoxy-chalcone (18) the observed product was the $p$-methoxy-benzaldehyde. When a B-ring methoxy was present in the orthoposition (19), the ratio of benzaldehyde to epoxide was 1:1 in the reaction mixture. This ratio increased to 2:1 when the methoxy was located in the meta-position (20) of the B-ring. Comparison of the results with the Hammett constants for a para- and meta-methoxy-group $\left(\sigma_{\mathrm{p}}=-0.27\right.$ and $\sigma_{\mathrm{m}}=$ 0.12 , respectively $)^{13}$ suggest that formation of the benzaldehyde versus the epoxide correlates with these values. When the methoxy-group is located in the meta-position the electron-withdrawing nature of the group becomes more apparent, due to the inductive effect, and the resonance electron-donor effects are minimal. Consequently, the reactivity of the benzylic carbon of the epoxide toward nucleophiles, such as a peroxyl anion, is minimized, thereby preventing the formation of the original benzaldehyde. Formation of the corresponding benzaldehyde is promoted when the B-ring contains a 3,4,5-trimethoxy- or a 3,4-dimethoxy-phenyl ring (compounds 12 and 16, respectively). Conversely, 
if the B-ring is multi-methoxy substituted but not at the 4-position, e.g. 14, the relative yield of the epoxide increases significantly.

\section{(ii) Electron withdrawing groups on the B-ring}

The epoxidation reactivity of the chalcones changed considerably when a nitro-group was present on the B-ring. Oxidation of para-nitro-compounds 9 and 10 with $\mathrm{H}_{2} \mathrm{O}_{2}$ and $\mathrm{K}_{2} \mathrm{CO}_{3}$ formed only the desired epoxide. This result was interesting because compound 18 (containing a methoxy- instead of a nitro-group) generated para-methoxybenzaldehyde as the major product; however, the reaction of compound 11 produced the epoxide exclusively. This observation indicates that the resonance and field-electron withdrawing effect of the meta-nitro-group overrides the resonance donating effect of the para-methoxy-group. This observation is consistent with the Hammett literature values of a nitroand a methoxy- group $\left(\sigma_{m}=0.71\right.$ and $\sigma_{p}=-0.27$, respectively). ${ }^{13}$ The results for chalcone 18 suggest that the epoxide might be formed followed by furtherreaction to produce the aromatic aldehyde. This reaction outcome could be a result of the electron-donating effect of the methoxy-group on ring-B, which stabilized the partial-positive charge on the benzylic position of the epoxide. Conversely, a nitro-group on the B-ring would destabilize the partial-positive charge at the same position, preventing the nucleophilic peroxide from adding, so hindering ring-opening of the epoxide to the corresponding benzaldehyde. Interestingly, during the synthetic study of the pyrazoles, it was found that a shorter oxidation procedure enhanced the desired epoxides to be isolated from the corresponding chalcone reaction, prior to epoxide decomposition.

Table 1: Percentage of products in each reaction, 'H-NMR studies.

\begin{tabular}{|c|c|c|c|c|}
\hline Chalcone & Chalcone $\%$ & Epoxide $\%$ & Benzaldehyde $\%$ & Acetophenone $\%$ \\
\hline $\mathbf{1}$ & 0 & 87.5 & 12.5 & 0 \\
\hline $\mathbf{2}$ & 42.9 & 28.6 & 14.3 & 14.3 \\
\hline $\mathbf{3}$ & negligible & 77.8 & 22.2 & 0 \\
\hline $\mathbf{4}$ & negligible & 66.7 & 16.7 & 16.6 \\
\hline $\mathbf{5}$ & negligible & 44 & 44 & 11.1 \\
\hline $\mathbf{6}$ & 39.6 & 39.6 & 20 & negligible \\
\hline 7 & negligible & 40 & 30 & 30 \\
\hline $\mathbf{8}$ & 35.7 & 35.7 & 14.3 & 14.3 \\
\hline $\mathbf{9}$ & 0 & 100 & 0 & 0 \\
\hline $\mathbf{1 0}$ & 0 & 100 & 0 & 0 \\
\hline 11 & 0 & 100 & 0 & 0 \\
\hline 12 & 0 & 25 & 75 & 0 \\
\hline 13 & 0 & 80 & 20 & 0 \\
\hline $\mathbf{1 4}$ & 0 & 69.3 & 23.1 & 7.6 \\
\hline $\mathbf{1 5}$ & 0 & 83.3 & 16.7 & 0 \\
\hline $\mathbf{1 6}$ & 0 & 0 & 100 & 0 \\
\hline $\mathbf{1 7}$ & 0 & 80 & 20 & 0 \\
\hline $\mathbf{1 8}$ & 0 & 14.3 & 85.7 & 0 \\
\hline 19 & 0 & 50 & 50 & 0 \\
\hline $\mathbf{2 0}$ & 0 & 66.7 & 33.3 & \\
\hline
\end{tabular}


(iii) Electron withdrowing groups on A-ring

${ }^{1} \mathrm{H}-\mathrm{NMR}$ spectra of the oxidized products of the chalcones containing an electron-withdrawing, 4methoxy-3-nitrophenyl, A-ring (2-8, Table 1) revealed the formation of complex product mixtures, irrespective of the nature of the substitutents located on the B-ring. These included the desired epoxide, original benzaldehyde, starting chalcone and, in some cases, original acetophenone, presumably formed from multiple reaction mechanisms, which we are currently investigating.

The reaction conditions were further assessed to determine whether both peroxide and base were required to convert the chalcones into the epoxides. This test was necessary to ensure that neither of the two reagents converted the chalcone into the apparent retro-Aldol products. Three chalcones were used in this study: chalcone 11, which generated $100 \%$ epoxide; compound 18, that produced predominately the substituted benzaldehyde; and chalcone 2, that gave a mixture of epoxide, benzaldehyde, acetophenone, and unreacted chalcone. The aforementioned chalcones were each reacted separately with peroxide in methanol (no base), and potassium carbonate in methanol (no peroxide), for 15 hours. In each case, only the starting chalcone was observed, as determined from the NMR spectra. These control experiments indicated that both the peroxide and the potassium carbonate are required to generate the epoxide from the chalcone. These reactions also confirm that the retroAldol products of the chalcone are not obtained by each of the reagents alone. Additionally, chalcones 2,11 , and 18 were treated with potassium carbonate, methanol and an equivalent amount of water (no hydrogen peroxide). In each of these experiments, only the starting materials were observed by NMR analysis, indicating that formation of the benzaldehyde from compounds $\mathbf{2}$ and $\mathbf{1 8}$ was not due to a retro-Aldol reaction.

In conclusion, the oxidation of chalcones with $\mathrm{H}_{2} \mathrm{O}_{2}$ and $\mathrm{K}_{2} \mathrm{CO}_{3}$ generated interesting results. The substituents on the A- and B-ring of the starting chalcones dictate the outcome of the reactions; substitution pattern on the B-ring is also important. Further studies are underway to gain further understanding on the structure, electronic effects and reactivity of these chalcone-epoxide systems.

Acknowledgements: The authors thank the National Science Foundation (REU and MRPG) for support.

\section{References}

1. (a) D.R. Palleros, J. Chem. Ed. 81, 1345 (2004); (b) J.R. Vyvyan, D.L. Pavia, G.M. Lampman and G.S. Kriz, J. Chem. Ed. 79, 1119 (2002); (c) N. Wachter-Jurcsask and H. Zamani, J. Chem. Ed. 76, 653 (1999); (d) C.E. Dixon and S.G. Pyne, J. Chem. Ed. 69, 1032 (1992).

2. (a) G.M. Tozer, V. E. Prise, J. Wilson, R. J. Locke, B. Vojnovic, M.R.L. Stratford, M.F. Dennis and D.J. Chaplin, Cancer Res. 59, 1626 (1999); (b) (i) R.W. Pero and D. Sherris, PCT Int. Appl. WO 20000484006 (2000); (ii) Chem. Abstr. 133, 198575 (2000); (c) G.M. Tozer, C. Kanthrou, C.S. Parkins and S.A. Hill, Int. J. Cancer 83, 21 (2002). 
3. N.J. Lawrence, D. Rennison, A.T. McGown, S. Ducki, L.A. Gul, J.A. Hadfield and N. Khan, J. Comb. Chem. 3, 421 (2001).

4. (a) M.L. Edwards, D.M. Stemerick and M.S. Sunkara, J. Med. Chem. 33, 1948 (1990); (b) R. DeVincenzo, C. Ferlini, M. Distefano, C. Gaggini, A. Riva, E. Bombardelli, P. Morazzoni, P. Valenti, F. Belluti, F.O. Ranellettie, S. Mancuso and G. Scambia, Cancer Chemother. Pharmacol. 46, 305 (2000).

5. H.N. Pati, H.L. Holt, Jr., R. LeBlanc, J. Dickson, M. Stewart, T. Brown and M. Lee, Med. Chem. Res. (2005) in press.

6. (a) H. K. Hsieh, L.T. Tsao, J.P. Wang and C.N. Lin, J. Pharm. Pharmacol. 52, 163 (2000); (b) H.K. Hsieh, T.H. Lee, J.P. Wang, J.J. Wang and C.N. Lin, Pharm. Res. 15, 39 (1998).

7. R. LeBlanc, J. Dickson, T. Brown, M. Stewart, H.N. Pati, W. Pennington, H.L. Holt, Jr. and M. Lee, Bioorg. Med. Chem. (2005) in press.

8. K. Ohsumi, T. Hatanaka, K. Fujita, R. Nakagawa, Y. Fukuda, Y. Niher, Y. Suga, Y. Morinaga, Y. Akiyama and T. Tsuji, Bioorg. Med. Chem. Lett. 8, 3153 (1998).

9. F.A. Wagner, Jr., US Patent 3, 896, 144 (1975).

10. (a) C. Lauret and S.M Roberts, Aldrichchimica Acta 35, 47 (2002); (b) C.J. Adams and L. Main, Tetrahedron 47, 4959 (1991). (c) J.P.J. Marais, D. Ferreira and D. Slade, Phytochem. (2005) in press.

11. G.P. Moloney, J. Chem. Ed. 67, 617 (1990).

12. Epoxidation of each chalcone was performed using this general method. A sealed mixture of chalcone $\left(20 \mathrm{mg}\right.$ ), $35 \% \mathrm{H}_{2} \mathrm{O}_{2}$ (9 mol equiv.), $\mathrm{K}_{2} \mathrm{CO}_{3}$ ( $3 \mathrm{~mol}$ equiv.) and $\mathrm{MeOH}\left(1.5 \mathrm{~cm}^{3}\right)$, was stirred overnight $(15 \mathrm{~h})$. The solvent was evaporated under reduced pressure, and the obtained residue partitioned between $\mathrm{CH}_{2} \mathrm{Cl}_{2}\left(40 \mathrm{~cm}^{3}\right)$ and $\mathrm{H}_{2} \mathrm{O}\left(10 \mathrm{~cm}^{3}\right)$. The organic layer was collected, dried with anhydrous $\mathrm{Na}_{2} \mathrm{SO}_{4}$, the crude product dissolved in $\mathrm{CDCl}_{3}$ and analyzed using $300 \mathrm{MHz}{ }^{1} \mathrm{H}-\mathrm{NMR}$ spectrometry. For example: 2,3-Epoxy-1-(3',4',5'-trimethoxyphenyl)3-(4"-nitrophenyl)propanone. Chalcone 10 was reacted to produce the epoxide as ayellow solid (78\%). Mp $140{ }^{\circ} \mathrm{C} ;{ }^{1} \mathrm{H}$ NMR $\left(\mathrm{CDCl}_{3}\right) \delta 3.91$ (s, 6H), 3.95 (s, 3H), $4.18(\mathrm{~d}, 1 \mathrm{H}, J=1.75 \mathrm{~Hz}$ ), $4.23(\mathrm{~d}, 1 \mathrm{H}, J=1.75 \mathrm{~Hz}), 7.30(\mathrm{~s}, 2 \mathrm{H}), 7.56(\mathrm{~d}, 2 \mathrm{H}, J=8.25 \mathrm{~Hz}), 8.28(\mathrm{~d}, 2 \mathrm{H}, J=8.25 \mathrm{~Hz}) ; \mathrm{IR}$ $(\mathrm{KBr}) \vee 3397,2936,2843,1679,1583,1520,1456,1415,1342,1162,1126,994,849 \mathrm{~cm}^{-1}$; MS (EI) $\mathrm{m} / \mathrm{z}$ (rel. intensity) $359\left(\mathrm{M}^{+}, 55\right), 195$ (100); HRMS $\left[\mathrm{M}^{+}\right]$for $\mathrm{C}_{18} \mathrm{H}_{17} \mathrm{NO}_{7}$ : obsd. 359.1010, calcd. 359.1005). ${ }^{?}$

13. C.D. Ritchie and W.F. Sager, Prog. Phys. Org. Chem. 2, 323 (1964).

Received on August 22, 2005. 